\title{
Lifestyle Factors Influencing Coronary Heart Disease
}

\author{
S. Sivajenani ${ }^{1}$, S. Kuillini and E. Madona \\ Department of Health Sciences, The Open University of Sri Lanka.
}

\begin{abstract}
This descriptive study examines the lifestyle factors influencing Coronary Heart Disease (CHD) patients in Teaching Hospital (TH) Jaffna. Jaffna has considerable incidence of CHD and there were high rates of admissions of acute and chronic CHD patients at $\mathrm{TH}$ Jaffna (Annual Hospital Statistics, 2014). Many cardiac treatments are available to prevent CHD in Jaffna but the incidences are still high. It is assumed that an active lifestyle may help to prevent these conditions. This study observed the lifestyle factors such as dietary habits, pattern of exercise, habit of smoking and alcohol intake.

The study has been carried out at the cardiology unit and all medical units of the TH Jaffna from the $15^{\text {th }}$ of November to the end of December 2014. 150 CHD patients were administered a questionnaires which were used to collect data. Convenience sampling technique was used to collect the sample.

This study has shown that CHD patients at TH Jaffna were initially affected by lack of exercises (75\%). Participants who followed an unhealthy dietary habit were $69 \%$ and participants who habitually smoked were $37 \%$ and alcoholics were $29 \%$.

This study revealed that most of the participants do not perform any exercise and follow unhealthy food habits. A significant number of participants are influenced by smoking and few of them are at risk of CHD by alcohol consumption.
\end{abstract}

Keywords: Coronary heart disease, dietary patterns, lifestyle factors, smoking, alcohol intake.

${ }^{1}$ Correspondence should be addressed to S. Sivajanani,

(Email: ssivajenani@yahoo.com) 


\section{Introduction}

CHD is the most important cause of death worldwide today. The numbers of CHD is still on the increase and it is estimated that in the coming years, the number of CHD patients will raise significantly, particularly in developing and transitional countries (Medicographia, 2009).

Life styles of CHD patients include non-smoking, acceptable amount of alcohol intake, proper dietary habits and engaging in physical activities. According to the British Heart Foundation (2009) men can drink no more than three to four units per day and women can drink no more than two to three units per day $(300 \mathrm{ml}$ beer, arrack $25 \mathrm{ml}$, $600 \mathrm{ml}$ toddy $=1$ unit). It is recommended that exercise daily for 30 to 60 minutes, like brisk walking, swimming and cycling, eating small fishes, vegetables, fruits, and avoiding fatty food, meat, beef, butter, coconut milk, prawn, crab, Cuttle fish and big fish can reduce CHD (Cadi Research Foundation, 2012).

In the general population, the risk of cardiac mortality is reduced by $50 \%$ in those who stop smoking, $20 \%$ to $30 \%$ by engaging in moderate physical activity, and $15 \%$ to $40 \%$ by adopting a combination of healthy dietary habits (limited intake of saturated fats, regular fish consumption, sufficient fruit and vegetable intake, and limited salt consumption (Cadi Research Foundation, 2012).

According to a recent study from Australia(Cadi Research Foundation, 2012), about nine billion of Australians could have been saved in 2008 if they had taken care of smoking, high-alcohol consumption, high body mass index (BMI), physical inactivity, inadequate fruit and vegetable intake (less than 3 servings per day).

Wijekoon (2013) stated that CHD is placed as the first cause for hospital mortality and the lifestyle is the key influencing factor of CHD. The average total fat intake of Sri Lankans contributes to $25 \%$ of total energy, with $80 \%$ of that consisting of saturated fat from coconut products, meat, milk, and oil. With regard to the type of dietary fatty acids, Sri Lankans consume nine times more saturated fats than polyunsaturated fatty acids compared with the current suggested ratio (less than one). According to statistics of the National Authority on Tobacco and Alcohol (NATA) smoking takes life of 50 to 60 people every day and approximately, four billion cigarettes are sold daily in the Sri Lankan market (Cadi Research Foundation, 2012). 
CHD Deaths in Sri Lanka reached 15,961 or $11.69 \%$ of total deaths (WHO, 2011). Last year's statistics of TH Jaffna (2014) indicate that 4500 patients were admitted to the cardiology ward for heart disease complications of which 500 patients were CHD. Further, the number of patients who were admitted for cardiac intervention such as Angiogram and angioplasty was not segregated. Considering the above cases, available material resources such as monitoring beds, cardiac ward beds, infusion pumps, instruments used for Angiogram, Electrocardiographic machines, Exercise tolerance test machines, and other instruments and human resources such as doctors, nurses, attendants and laborers are inadequate to give quality treatment at TH Jaffna.

It is necessary to think broadly about the life style in Jaffna as it has greater influence on CHD. This study will help to raise the awareness on the need to change our lifestyle for better health.

\section{Methodology}

This is a quantitative descriptive study. Purpose of this study is to find out which life style factor has mostly influenced CHD among Jaffna population and educate the public on modifying their life style patterns accordingly and raise the awareness of health care professionals for best practices in preventing them.

The data collection was done in TH, Jaffna. It is the one and only tertiary care hospital in the Northern Province with advanced facilities and specialized units including the cardiology unit. That is the reason why many patients visit Jaffna TH from neighboring areas to get treatment. Participants were selected from the cardiology unit, cardiac ward and eight medical wards including four female wards $(1,2,3$, and 4$)$ and four male wards $(7,8,9$, and 10) at Jaffna Hospital. Bed strength of each medical ward is about 40, cardiology ward bed strength is 16 and cardiology unit bed strength is six. There are six Nursing Officers and a Ward Manager working in each medical ward. Cardiology ward and coronary care unit are both under a Nurse In- charge and 14 Nursing Officers.

Convenience sampling method was used to select the sample. This was one of the sampling methods of non-probability sampling. It was most suitable for this research study, because people who were unsuitable for the sampling study have already been eliminated, so only the most suitable candidates remained. So this process became 
less time consuming and the costs carried out for the sampling project were greatly reduced.

Many patients with several diseases come for inward treatment in TH, Jaffna. Among them the investigators selected all patients with CHD in TH, Jaffna as the accessible population in this study. Sample collection was done on non-visiting hours every day without interfering with the nursing care. The exclusion criteria of the sample was mentally and emotionally disabled people, deaf and blind persons, illiterate people, those who were diagnosed as CHD with other diseases and critically ill CHD patients.

Self-administered questionnaires were used to collect data to identify which life style factor influences CHD patients at TH Jaffna and the questionnaire was developed originally in English and then translated to Tamil and Sinhala Languages under the guidance of the research Supervisor. The questionnaire consisted of a series of questions covering the areas such as section A - socio-demographic information of the participants; section B - information about the disease and admission; and the section $\mathrm{C}$ - life style pattern which includes assessment of dietary habits, exercise patterns, alcohol and smoking habits.

Reliability and validity were maintained by extensive discussion and corrections done with the Ethical Review board, University of Jaffna and with the supervisor. The questionnaire was tested through a pilot study done at Medical unit, TH Jaffna. According to the results of pilot study, the questionnaire was modified appropriately.

\section{Date Collection and Analysis}

Data was collected at the medical and cardiology unit, TH Jaffna from $15^{\text {th }}$ of November to end of December 2014. After the approval of the Ethical Review Board of the University of Jaffna, permission was obtained from the Director of TH Jaffna as well as ward consultants. On the third day of admission, the letter of invitation was given to the participants for those, with confirmed diagnosis by the doctor and for patients who were transferred from the coronary care units to wards. The investigators went to the wards in the evening and obtained permission from the ward staff to hand over the informed consent form and self-administered questionnaire to the participants. Instructions and explanations was given to participants regarding all questions nearly for one hour, then they 
were asked to complete the questionnaire and hand it over to the nursing officers to keep in the box provided by the researchers. Afterwards, those questionnaires were collected by the researchers. 150 participants participated and the response rate was $100 \%$. Data was collected in one month.

After completion of data collection, the data was transferred to SPSS 16 (statistical package of social science) and was analyzed according to the specific general objectives. The frequency of each need item was calculated and the associations of particular needs with particular variables were analyzed. Some of the questions were not answered by the participants; such questions were mentioned in the results.

\section{Results}

The present study focused on the lifestyle factors influencing CHD patients at TH Jaffna and the results of the study were analyzed according to the specific objectives. Socio demographic data, disease history, dietary habit, pattern of exercise and habit of alcohol and smoking will be given in tables and charts as well as explanation also will be presented.

Table 1. Demographic Data $(n=150)$

\begin{tabular}{|c|c|c|}
\hline Characteristics & Number of Patients & Percentage \\
\hline Age Group 31- 40 & 2 & 1.3 \\
\hline $41-50$ & 10 & 6.7 \\
\hline $51-60$ & 30 & 20.0 \\
\hline $61-70$ & 70 & 46.7 \\
\hline $71-80$ & 35 & 23.3 \\
\hline $81-90$ & 3 & 2.0 \\
\hline Gender & 93 & 62.0 \\
\hline Female & 57 & 38.0 \\
\hline Hinduism & 121 & 80.7 \\
\hline Islam & 6 & 4.0 \\
\hline Christianity RCL & 15 & 10.0 \\
\hline Christianity NRC & 8 & 5.3 \\
\hline \multirow{2}{*}{ Marital Status Unmarried } & 5 & 3.3 \\
\hline & 143 & 95.3 \\
\hline & 2 & 1.3 \\
\hline$\frac{\text { Wrdowed }}{\text { Level of Education }}$ & & \\
\hline No formal education & 4 & 2.7 \\
\hline
\end{tabular}




\begin{tabular}{|c|c|c|}
\hline \multicolumn{1}{|c|}{ Up to Grade 05 } & 38 & 25.3 \\
Grade 06- 11 & 49 & 32.7 \\
G.C.E O/L & 32 & 21.3 \\
G.C.E A/L & 21 & 14.0 \\
Graduate & 3 & 2.0 \\
Post Graduate & 3 & 2.0 \\
\hline Government Job & 25 & \\
Non-Government Job & 17 & 16.7 \\
Self-Employment & 61 & 11.3 \\
Missing Participants & 47 & 40.7 \\
Occupation & 17 & 31.3 \\
\hline Family Income & 25 & 11.3 \\
5,000 - 9,999 & 29 & 16.7 \\
10,000 -19,999 & 18 & 19.3 \\
20,000 -30,000 & 7 & 12.0 \\
$>30,000 \quad$ Missing Participants & 54 & 4.7 \\
& & 36.0 \\
\hline
\end{tabular}

A total of 150 patients were interviewed. Their ages ranged from 3090 years and a significant amount of participants $70-(46.7 \%)$ were between 61 to 70 years. There were $93(62 \%)$ males and $57(38 \%)$ females. $121(80.7 \%)$ participants were following Hinduism and 143 $(95.3 \%)$ were married. Educational level from grade 6-11 were 49 $(32.7 \%)$, while $21(14 \%)$ had qualified in the Advanced Level Examination. Out of the participants, 61 (40.7\%) were selfemployed, whereas, $42(28 \%)$ had white collar jobs.

Table 2. History of Disease and follow up $(n=150)$

\begin{tabular}{|c|c|c|}
\hline Characteristics & $\begin{array}{c}\text { Number of } \\
\text { Patients }\end{array}$ & Percentage \\
\hline Admissions for CHD & 73 & 48.7 \\
Only 01 time & 33 & 22.0 \\
02 times & 42 & 28.0 \\
O3 times & 2 & 1.3 \\
Not Answered & 139 & 92.7 \\
Clinic Follow up & 11 & 7.3 \\
Yes & & \\
No & 140 & 93.3 \\
Pattern of Regular Medication & 10 & 6.7 \\
Yes & 29 & 19.3 \\
No & 121 & 80.7 \\
\hline Family History & & \\
Yes & & \\
\hline
\end{tabular}


However, $42(28 \%)$ of the participants' family income was less than ten thousand (Table 1).Participants who regularly attended the cardiology clinic were $139(92.7 \%)$ and 140 (93.3\%) were taking medicine on a regular basis but $42(28 \%)$ were recurrently admitted to hospital for CHD. Most of the participants, 121 (80.7\%) did not have a family history of CHD (Table 2).

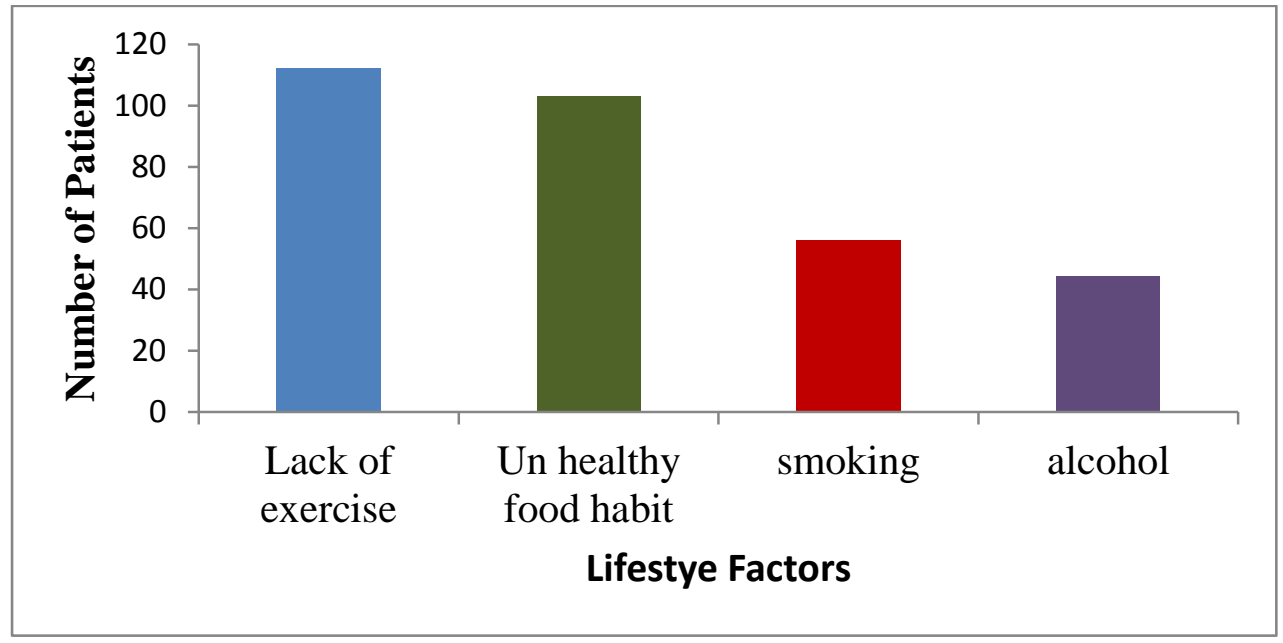

Figure 1. Influencing Lifestyle Factors of CHD at TH Jaffna

This study shows that CHD patients at TH Jaffna were mostly affected by lack of exercise (112) and a few 31 (20.7\%) were doing moderate physical activities. Hundred and three participants were following unhealthy dietary habits. Participants who habitually smoked were (56) and alcoholics were 44 (Figure 1).

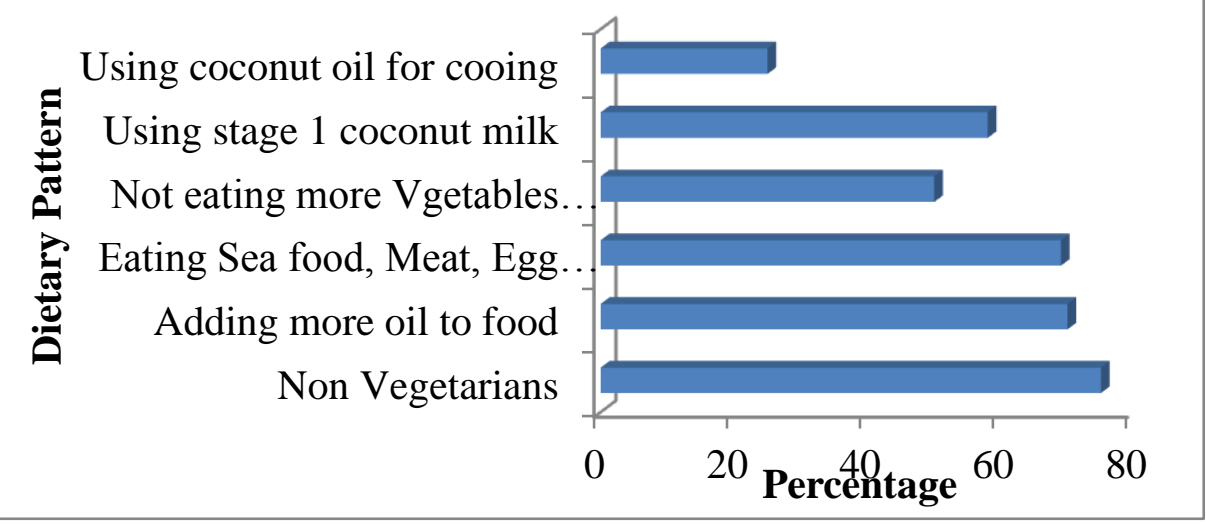

Figure 2. Dietary Pattern of the Participants 
Most of the participants were following unhealthy dietary habits. Eighty six $(57.3 \%)$ participants were adding stage 1 coconut milk (First milk prepared from coconut) and forty six (30.7\%) participants were using gingili oil but a significant amount of participants thirty eight $(25.3 \%)$ were adding coconut for cooking. There were $69 \%$ of the participants consuming large fish, meat, crabs, prawn, Cuttle fish and whole egg for more than two days in a week, whereas $24.5 \%$ of the participants were vegetarians. About $70 \%$ of the participants were adding oil in large quantity in food. There were $75 \%$ of the participants' not eating a large portion of vegetable and fruits (Figure 2).

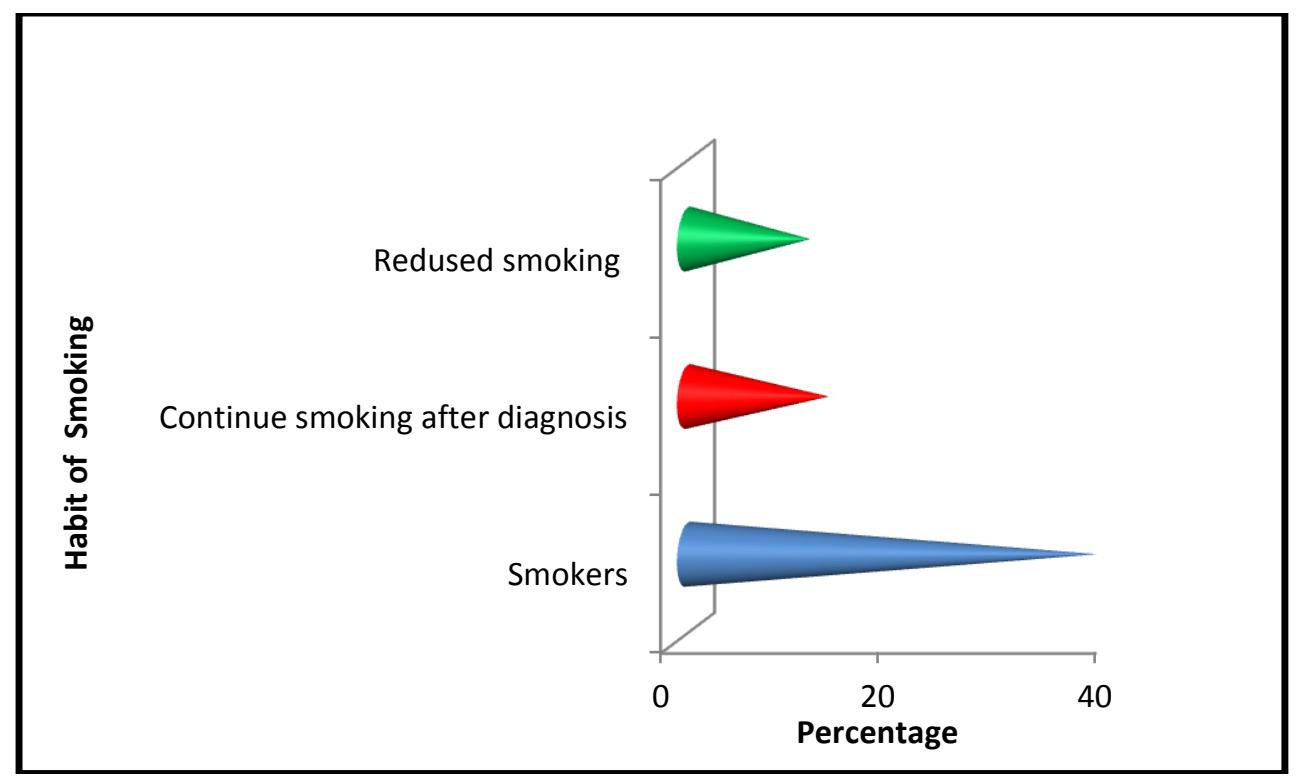

Figure 3. Habit of Smoking

Around $38 \%$ of the participants were smokers. Among them $13 \%$ of them were continuing smoking after diagnosis as CHD. However, $11.3 \%$ of the participants have reduced smoking compared to the past (Figure 3). 


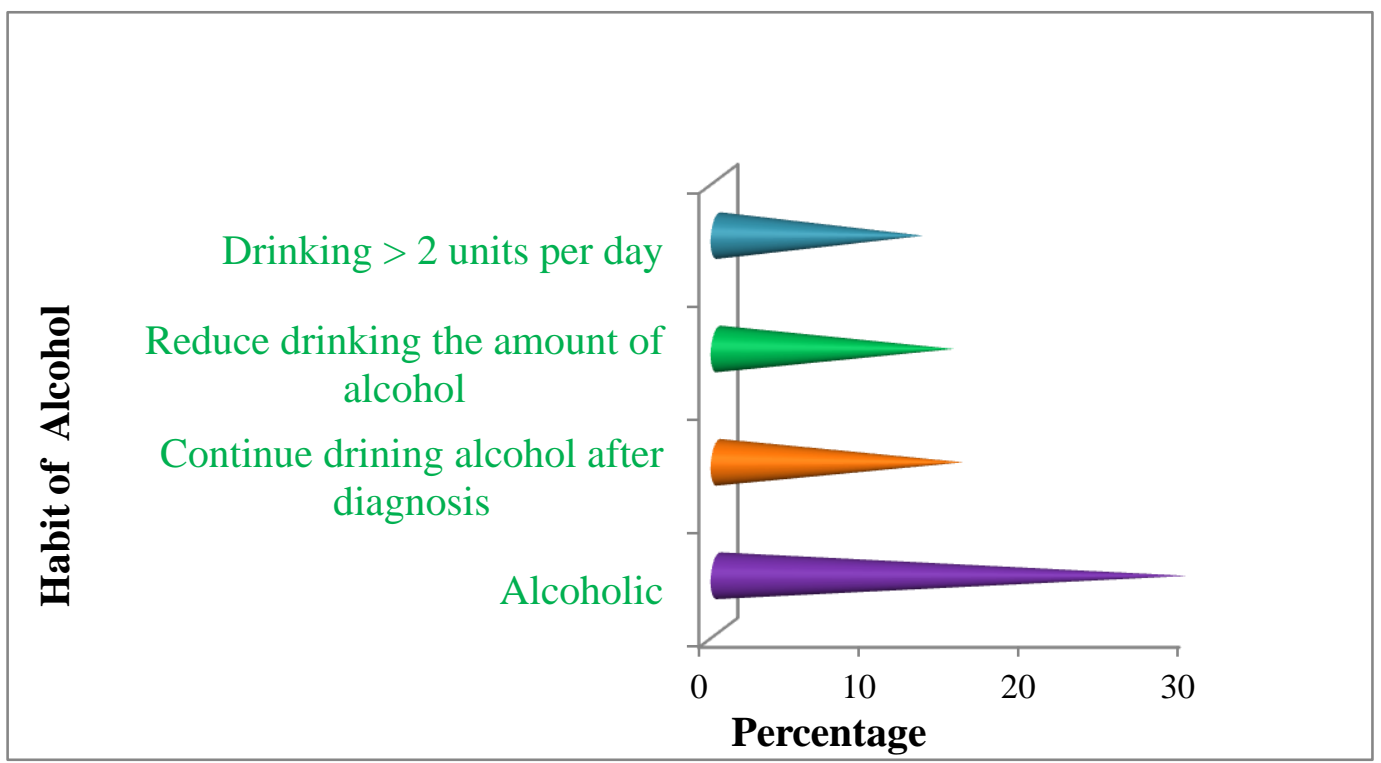

Figure 4. Habit of Alcohol

About $29 \%$ of the patients were consuming alcohol but $15.3 \%$ still continued drinking after diagnosis, though $14.7 \%$ of them had reduced drinking compared to the past. About $13 \%$ of the participants were drinking more than two units per day (Figure 4).

Results were given in relation to meet the specific objectives. Hundred and fifty participants participated and the interpretation of the findings will be discussed next.

\section{Discussion}

\section{Pattern of Exercise among CHD Patients at TH Jaffna}

The findings illustrated that the lack of exercise is the main influencing factor of CHD and a fewer number of the patients were doing exercise including vigorous activity and moderate physical activities. So the risk of CHD in TH Jaffna population may be at a lower level of physical activity as the same findings revealed in Taiwan (Tsai, Hsieh, Li, Chen \& Jeng, 2013). Exercise depends on the disease condition of patients. But this study did not analyze the functions of the heart of these patients. The reason may be that the doctor might not have prescribed exercise due to their disease condition. Therefore, lack of exercise cannot be considered as the most influencing lifestyle factor of CHD patients in TH Jaffna. 
Another reason may be the poor monthly income. A considerable number of cases were earning less than Rs.10,000 income per month. Therefore, they need to work more hours to earn extra money. Thus, they might not have the mentality of doing exercise in their stressful life.

\section{Dietary Habit of CHD Patients at TH Jaffna}

This study finding revealed that a significant number of the patients were using coconut oil for cooking. Studies on coconut oil have not proven whether it has good or bad fatty acids. Some studies stated that coconut oil has saturated fat and it will increase the Low Density Lipoprotein (LDL) and Triglycerides as well. Pehowich, Gomes \& Barnes (2000) stated that coconut oil is good for the heart because it has median chain fatty acids (MCFA), which increases the High Density Lipoprotein (HDL). They also claim that virgin coconut oil is good for the heart but it was difficult to draw a conclusion whether the participants were adding virgin coconut oil or not because it is expensive and they are unable to get pure virgin coconut oil in the markets. Therefore, further research is needed to prove that the coconut oil is heart healthy. Therefore, adding coconut oil is considered as unhealthy in this study. More than half of the patients were using stage $01(1 \mathrm{st}$ milk juice prepared from coconut) coconut milk for cooking.

Small fish is good for the heart because it has omega 3 fatty acids. It decreases triglyceride levels; slows the growth rate of atherosclerotic plaque. However, coronary artery disease patients may not be able to get enough omega-3 by diet alone. These people may want to talk to their doctor about taking a supplement but big fish has too much of cholesterol. American Heart Association (2015) recommend eating fish (small fish) at least two times (Two servings) a week. Most of the patients were eating a considerable amount of sea foods (Big fishes, Crab, Cuttle fish \& Prawn), egg and meat varieties.

So this finding indicates that the participants did not have enough knowledge regarding proper food habits for CHD and the unhealthy food habit is another influencing factor on the causation of CHD among the participants. It increases the risk of CHD even when they are on treatment. Similar results were found in a study by Vest fold Heart care Study Group (2003) and Hu (2009).

Results revealed in the study may be due to the habit of eating rich fatty food by participants since childhood because Sri Lankans mostly consume saturated fats from coconut products, meat, milk 
and oil. Similar findings have been drawn by Cadi Research Foundation, 2012. Another reason could be, most of the participants were males and self-employed, hence unable to attend to proper food. Their educational level is also less because most of the participants studied only until grade 6 to 11 .

\section{Habit of Smoking Influencing CHD Patients at TH Jaffna}

The findings demonstrate a significant number of participants affected by smoking and it is the third influencing lifestyle factor of CHD patients at TH Jaffna because most of the participants were male and more than half of them were self-employed such as drivers, mechanics, laborers, fishermen. A considerable number of participants continued smoking after diagnosis of CHD. So the risk of CHD among these people is high as found in United States (Bazzano, et al, 2003) and Japan (Hata et al, 2011).

\section{Pattern of Alcohol Intake of CHD Patients at TH Jaffna}

This study shows that a considerable number of participants were influenced by alcohol consumption in TH Jaffna. Even though the vast majority of participants still continuing, contrast findings drawn to Rimm, Williams, Fosher, Criqui and Stampfer (1999).

Moderate consumption decreases the risk of heart disease, whereas; high level of intake increases the risk. Here in this study, a significant number of participants, mostly male participants, were taking alcohol more than two units per day which is harmful to the heart $\mathrm{a}$ and considerable number of participants have the habit of both smoking and consuming alcohol so they are considered as at risk.

\section{Conclusion}

CHD patients in TH Jaffna are mainly influenced by an unhealthy dietary habit such as excessive use of $1^{\text {st }}$ stage of coconut milk, coconut oil for cooking. Eating meat, large fish, crabs, cuttle fish, and prawn for more than two days a week and also less consumption of vegetables and fruits as supplementary items have also contributed to CHD.

This study finding also revealed that substantial proportions of CHD patients in TH Jaffna did not have regular exercise and that a 
considerable number of participants was influenced by smoking and a few of them were at risk of CHD due to alcohol consumption.

\section{References}

American Heart Association (2015). Fish 101, Retrieved from http:/ / www.heart.org/HEARTORG/GettingHealthy/NutritioC enter/Fish-101_UCM_305986_Article.jsp

Annual Hospital Statistics (2014). Teaching Hospital Jaffna.

Basavanthappa, B. T. (1998). Nursing research (1 ${ }^{\text {st }}$ Ed). Delhi: Lordson Publishers (P) Ltd.

Bazzano, L. A., He, J., Muntner, P., Vupputuri, S. \& Whelton, P. K. (2003). Relationship between cigarette smoking and novel risk factors for cardiovascular disease in the United States. Annals of Internal Medicine. 138(11) 891-7.

Burns, N. \& Grove, S. K. (2005). The Practice of Nursing Research: Conduct, Critique, and Utilization ( $5^{\text {th }}$ Ed). St. Louis, Elsevier Saunders.

Cadi Research Foundation (2012). Coronary Artery Disease in Asian Indians. Retrieved from http://www.cadiresearch.org

Clark, P., Creswell, J. W. \& Vicki, L. (2010).Understanding research: a consumer's guide: Pearson Publishers.

De Backer, G. (2009). The global burden of coronary heart disease. Medicographia. Retrieved from http:/ /www.medicographia.com/2010/07/the-global-burdenof-coronary-heart-disease /

Doordan, A. M. (1998). Research survival guides (1st Ed). Philadelphia: Lippincott. Frank, B. \& Willett, W. C. (2002) Optimal Diets for Prevention of Coronary Heart Disease Free. The Journal of the American Medical Association. 228 (20) 2569-2578. 
Hata, J., Doi, Y., Ninomiya, T., Fukuhara, M., Ikeda, F., Mukai, N., Hirakawa, Y., Kitazono, T \& Kiyohara, Y. (2011). Combined Effects of Smoking and Hypercholesterolemia on the Risk of Stroke and Coronary Heart Disease in Japanese: the Hisayama study: Cerebrovascular Disease.US National Library of Medicine National Institutes of Health 31(5) 47784.

Industrial Research Institute(2010). Research management. Michigan: Industrial Research Institute

Locke, L. F., Silverman, S.J. \& Spirduso, W. W. (2010). Reading and Understanding of Research ( $3^{\text {rd }}$ ed). California: Sage Publications.

Merom, D., Sinnreich, R., Aboudi, V., Kark, J., D. \& Nassar, H. (2012). Lifestyle Physical Activity among Urban Palestinians and Israelis. BMC Public Health.

Mittal, S. (2006). Coronary Heart Disease in Clinical Practice. Springer Science \& Business Media.

Pehowich, D. J., Gomes, A. V. \& Barnes, J. A. (2000).Fatty acid composition and possible health effects of coconut constituents. The West Indian Medical Journal. 49(2): 12833.

Rim, B. E., Williams, P., Fosher, K., Criqui, M. \& Stampfer, S. J., (1999) Moderate alcohol intake and lower risk of coronary heart disease: British Medical Journal, Retrieved 11-12-2000, http://www.bmj.com/content/319/7224/1523?linkType=FU LL\&resid=319/7224/1523 \&journal Code $=$ bmj

Sivagnanasundram, C., (2003). Learning research,(2 $\left.{ }^{\text {ndEd}}\right)$. Nallur: Boasco Arton printer.

Tsai, C., Hsieh, M. H. Li. A. H., Chen, P. L., \& Jeng, C., (2013). Dietary supplementation and engaging in physical activity as predictors of coronary artery disease among middle aged women. The Journal of Clinical Nursing. Retrieved June 7, 2013, fromhttp://www.ncbi.nlm.nih.gov/pubmed/23742157

Wijekoon, N., (2013).Total Risk Approach for Primary Prevention of CVD: 3rd Foundation Sessions of the Ceylon College of Physicians. 
Vestfoldheartcare study group (2003). Influence on lifestyle measures and five-year coronary risk by a comprehensive lifestyle intervention programme in patients with coronary heart disease. European Journal of Cardiovascular Prevention and Cardiac Rehabilitation. Retrieved December 10, 2003, from http://www.ncbi.nlm.nih.gov/pubmed/?term=Vestfold Heart care Study.

Received: 27-4-2015 Revised: 2-7-2015 Accepted: 4-7-2015 